\title{
Age and leadership: comparisons of age groups in different kinds of work environment
}

\author{
Gerry Larsson
}

Department of Security, Strategy and Leadership, Swedish Defence University, Karlstad, Sweden and Department of Public Health, Inland Norway University of Applied Sciences, Elverum, Norway, and

The Institute of Environmental Medicine, Karolinska Institutet, Stockholm, Sweden

\begin{abstract}
Purpose - The purpose of this study is twofold. First, to compare the self-rated leadership behaviors, leadership-related competencies and results of the leadership of younger, mid-aged and older leaders; and second to compare these aspects among younger leaders in different kinds of the work environment and between men and women.

Design/methodology/approach - Data was collected using the developmental leadership questionnaire from a sample of Swedish leadership course participants $(N=7,743)$.

Findings - The results showed that the younger group of leaders (29 years old or younger $n=539)$, rated themselves more negatively than the mid-aged (30-50 years, $n=5$,208) and older ( 51 years or older, $n=1,996$ ) leaders. Analysis of the group of younger leaders showed that those working in the private sector scored most favorably. The gender comparison revealed that young male leaders scored higher on negative conventional (transactional) and destructive leadership behaviors. A logistic regression analysis of the younger group showed that social competence, developmental leadership and destructive leadership (negative) influenced self-rated results of leadership.

Research limitations/implications - The study is based on leaders' self-ratings only.

Practical implications - The results can be used in leadership development contexts and in individualized coaching or mentoring programs.

Originality/value - The results have new implications for leadership theory related to self-confidence, stereotypes, selection and organizational culture.
\end{abstract}

Keywords Leadership, Work environment, Age, Theory-based measurement,

Developmental Leadership Questionnaire (DLQ)

Paper type Research paper

\section{Introduction}

According to recent labor polls, young people have shown an increasing reluctance to take on leadership positions, at least in Sweden (Fjällberg, 2012; Ledarna, 2014). The studies

(C) Gerry Larsson and Christina Björklund. Published by Emerald Publishing Limited. This article is published under the Creative Commons Attribution (CC BY 4.0) licence. Anyone may reproduce, distribute, translate and create derivative works of this article (for both commercial and noncommercial purposes), subject to full attribution to the original publication and authors. The full terms of this licence may be seen at http://creativecommons.org/licences/by/4.0/legalcode

The research was funded by AFA Insurance.

Received 20 January 2020 Revised 28 April 2020 Accepted 14 June 2020 
MRR 44,5

show that many in the younger generation do not find the organizational demands and expectations worth fighting for Rorstorm (2005). Recent studies have noted that leaders today, irrespective of age, experience high demands in working life. Typical comments concern long hours, high demands and difficulty in finding time for recovery and private life (Ipsen and Jensen, 2012). Female leaders report more such concerns than male leaders (Björklund et al., 2013; Ipsen and Jensen, 2012; Skakon and Kristensen, 2011). For young people, these demands and the challenge of taking on one's first leadership position coincide with the time in life when many start a family (Lyons and Kuron, 2014). However, findings are not unambiguous, with one study showing that young managers do indeed want to advance their careers, but on the condition that it is possible to balance working life with private life (Franzén et al., 2002).

Thus, findings are mixed and during the past years a more positive trend concerning younger peoples' propensity to take on a leadership position has also been shown (Vision, 2018). This makes it important for organizations to create opportunities and support to younger managers just entering the position, as young managers are influential and begin their development as soon as they begin their careers (Benjamin and O'Reilly, 2011).

Another challenge as a young leader is that taking on a leadership or managerial role not only involves learning new tasks but also developing an identity as a leader (Hill, 1992). This identity grows from the experience in a leadership role of encounters with other people in different social contexts (Ibarra et al., 2010). Before gaining all this experience, it may take some time before a young person can see him- or herself as a leader or manager. One interview study, which followed eight first-time managers over time, concluded that the managers' work identity was constantly oscillating as the result of an ongoing dialectic between continuity and change, progress and standing-still, knowing and not-knowing and excitement and despair. It concluded that the best way of helping young leaders to grow into their leadership role is to focus on learning from the challenges, problems and dilemmas already present in the managers' everyday working lives (Bolander et al., 2019). Results from another interview study of young leaders show that the professional identity as a leader is constructed through a process of creative imitation, in which emotions play an important role in the performance of the professional identity (Åkerblom, 2011). Through these kinds of process, an individual who looks upon him- or herself as a leader may eventually come to think and act like one (Ligon et al., 2011).

Taking on a leadership position involves both coping with demands and developing an identity as a leader. This raises the question of whether there will be a shortage of young people entering leadership positions in the future.

A common theme in age-oriented leadership research is the stereotype construct, which implies that members of a certain group, for instance young adults, are expected to share characteristics and exhibit behaviors that are typical of their group (Corsini, 1999). It has repeatedly been shown that people expect older leaders to be more experienced and responsible and to use more authoritarian power at times of stress (Antonakis, 2011; Bass and Bass, 2008; Kakabadse et al., 1998). However, the generality of this in leadership contexts has begun to be questioned. The importance of age and seniority has been found to vary between different kinds of organizations (Oshagbemi, 2004). Indeed, the opposite of the stereotype is sometimes found, particularly in rapidly changing technology firms Bass and Bass (2008).

Young leaders in working life have been found to face certain age-related challenges. One of these is establishing trustworthiness in relation to older subordinates (Benjamin and O'Reilly, 2011). Due to lack of experience, young leaders may also be at a disadvantage when it comes to understanding others' lives and having the interpersonal competencies needed 
when communicating with others with different backgrounds (Benjamin and O'Reilly, 2011; Uen et al., 2009). Prensky (1998) argued that personnel under 30 years of age need to be treated differently by supervisors and colleagues. They have grown up with advances in technology and have different cognitive styles than older people (Bass and Bass, 2008). Some measures have been proposed, which might make it easier for young leaders. These include creating developmental possibilities early (Benjamin and O'Reilly, 2011), mentoring (DeLong et al., 2008) and more flexible working conditions (Tulgan, 2011). However, summing up, Pintonakis (2011) claims that the field of age and leadership is severely underresearched.

In the present study, an attempt was made to fill some of the knowledge gaps about young leaders. These gaps include possible general differences between younger and older leaders. The question of potential differences between young leaders in different kinds of work environment also appears to be under-researched. Possible gender differences among young leaders also need further exploration. Finally, there is also a shortage of theoreticallybased analyzes of the relative contribution to outcome measures of the leadership of personrelated factors such as skills; context-related factors such as type of work environment; and leadership behaviors.

The ambition of the present study was to take leaders' own experiences as a point of departure and to study age-related aspects of self-reported leadership behaviors, based on an established leadership model and paying attention to gender and different kinds of the work environment. The aim was: to compare the self-rated leadership behaviors, leadershiprelated competencies and results of the leadership of younger, mid-aged and older leaders, to compare the self-rated leadership behaviors, leadership-related competencies and results of young male and female leaders' leadership in different types of the work environment and to analyze how theoretically-derived predictor variables contribute to self-rated results of leadership among younger leaders.

\section{The leadership model}

The current study draws on "the leadership model," a form of the transformational leadership model, which has been adapted for use in Scandinavia (Larsson et al., 2003, 2018). This model is presented below.

According to the leadership model, the actual behavior of a leader depends on the interaction between a number of leaders and contextual characteristics. In theoretical terms, this means that the model is based on the interactional person-situation paradigm (Endler and Magnusson, 1976). Leader characteristics involve two components, namely, basic prerequisites and desirable skills. The basic prerequisites impact the development of desirable skills. The higher the level of basic prerequisites possessed by the individual leader, the greater is his or her potential to develop desirable skills. The model also makes the assumption that a favorable combination of basic prerequisites and desirable skills constitutes a prerequisite for successful leadership. However, none of these is sufficient in itself because leadership is also affected by contextual factors (Larsson et al., 2003; Larsson and Hyllengren, 2013).

The contextual characteristics shown in Figure 1 should be regarded as examples. The illustration demonstrates that groups and organizations influence one another. The same applies to organizations and the environments in which they operate. All organizations group their members together in some sort of structure. Every group develops its own group culture to manage its external environment, while also being affected by the organizational culture and structure. As shown in Figure 1, the model presents three different types of leadership styles, namely, developmental leadership, conventional leadership and 


\section{MRR}

44,5

664
Figure 1.

The leadership model

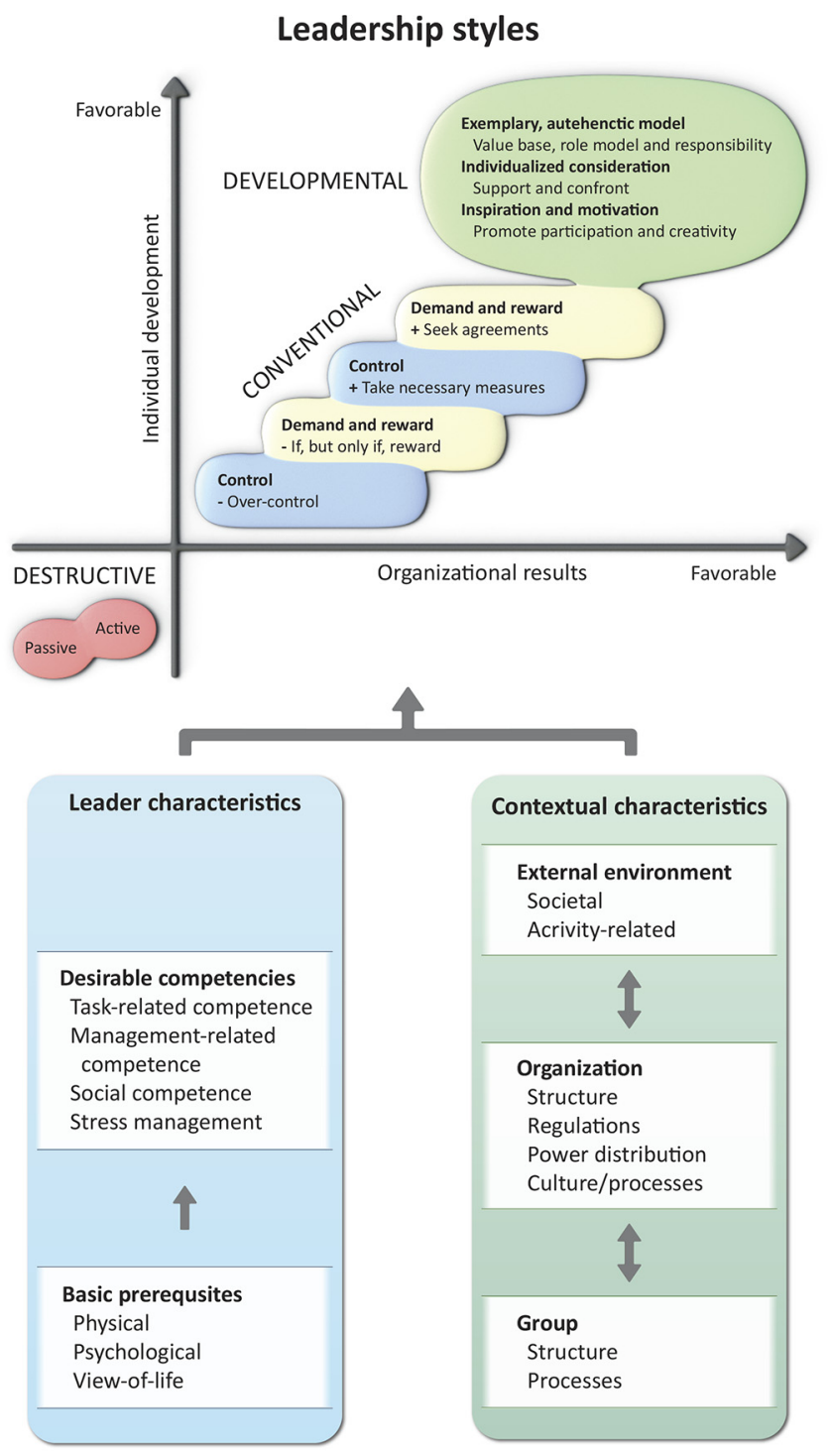

Source: Larsson et al. (2018) reprinted with permission from Studentlitteratur AB

destructive leadership. Each of these leadership styles has a hierarchical model structure (which includes factors such as exemplary and authentic model), sub-factors, (e.g. value base) and multiple behaviors at the lowest level (the last-mentioned not shown in Figure 1). The model also describes a relationship between different types of leadership behaviors, where leaders differ in the extent to which they exhibit these behaviors. Hence, the model 
should not be regarded as typology classifying leaders into different categories. All leaders use various styles to a greater or lesser extent. We have placed the different types of leadership styles in a coordinate system with the axes representing organizational performance and individual development. Organizational performance relates to more objective outcomes measures such as productivity and sick leave. Individual development refers to the leader gradually using developmental leadership behaviors more and more, which subsequently also results in individual development in the organization (Larsson et al., 2003, 2018).

The argument for choosing the leadership model is that it draws on the transformational leadership model, the most widely used leadership model in leading scientific journals in recent decades (Bass and Riggio, 2006; Diaz-Sáenz, 2011). It also draws on the authentic leadership model (Gardner et al., 2005). We also regarded the roots of the model in the interactional person-situation paradigm (Endler and Magnusson, 1976) and the Scandinavian adaptation of the original American models, as strengths, which make the model an appropriate point of departure for a gender-oriented leadership study in Sweden (Larsson et al., 2018).

\section{Method}

Participants

The sample consisted of all leaders participating in developmental leadership courses conducted by trainers authorized by a Swedish university from July 2017 to June 2019 ( $N=$ 7,743). Prior to these courses, each leader rated him- or herself on the Developmental Leadership Questionnaire [DLQ, Larsson (2006)]. The leaders (course participants) accessed the DLQ via a Web-based link. The response rate is estimated as $100 \%$ because the leadership courses use the participants' responses as a point of departure.

Before responding to the questionnaire, participants are informed that their responses may be used anonymously for research purposes. They can then choose to agree to this or not, without this having an effect on their leadership course. In the present study, everyone consented. The study was carried out in accordance with the ethical principles of human research (Swedish Research Council, 2002), i.e. the principle of respect for autonomy, beneficence, nonmaleficence and justice.

Background data (\%) for the study group is presented in Table 1.

Table 1 is divided by age and type of work environment. The table shows that the background variables gender, education, position and type of work environment vary significantly between the three age groups. In the younger group (which is by far the smallest group of leaders), differences between the three types of work environment are noted for gender and education. The lower number of participants in the younger group shown in Table 1 (397 instead of 539) is because of the fact that the missing individuals had chosen the response alternate "other" for the question about a type of work.

\section{Measures}

The DLQ, based on a structural equation modeling analysis (Larsson, 2006), was used to assess leadership behaviors. Developmental leadership is a leadership style with 21 items designed to measure the three factors, namely, exemplary, authentic model, individualized consideration and Inspiration and motivation. Sample item: "I act in accordance with the opinions I express." Conventional-positive leadership is a leadership style measured using six items covering the facets demand and reward - seek agreements and control - take necessary measures. Sample item: "I aim to reach agreements on what must be done." The factor conventional-negative leadership is also assessed using six items, measuring the two 
\begin{tabular}{l} 
MRR \\
44,5 \\
666 \\
\hline
\end{tabular}

Table 1.

Description of the study group

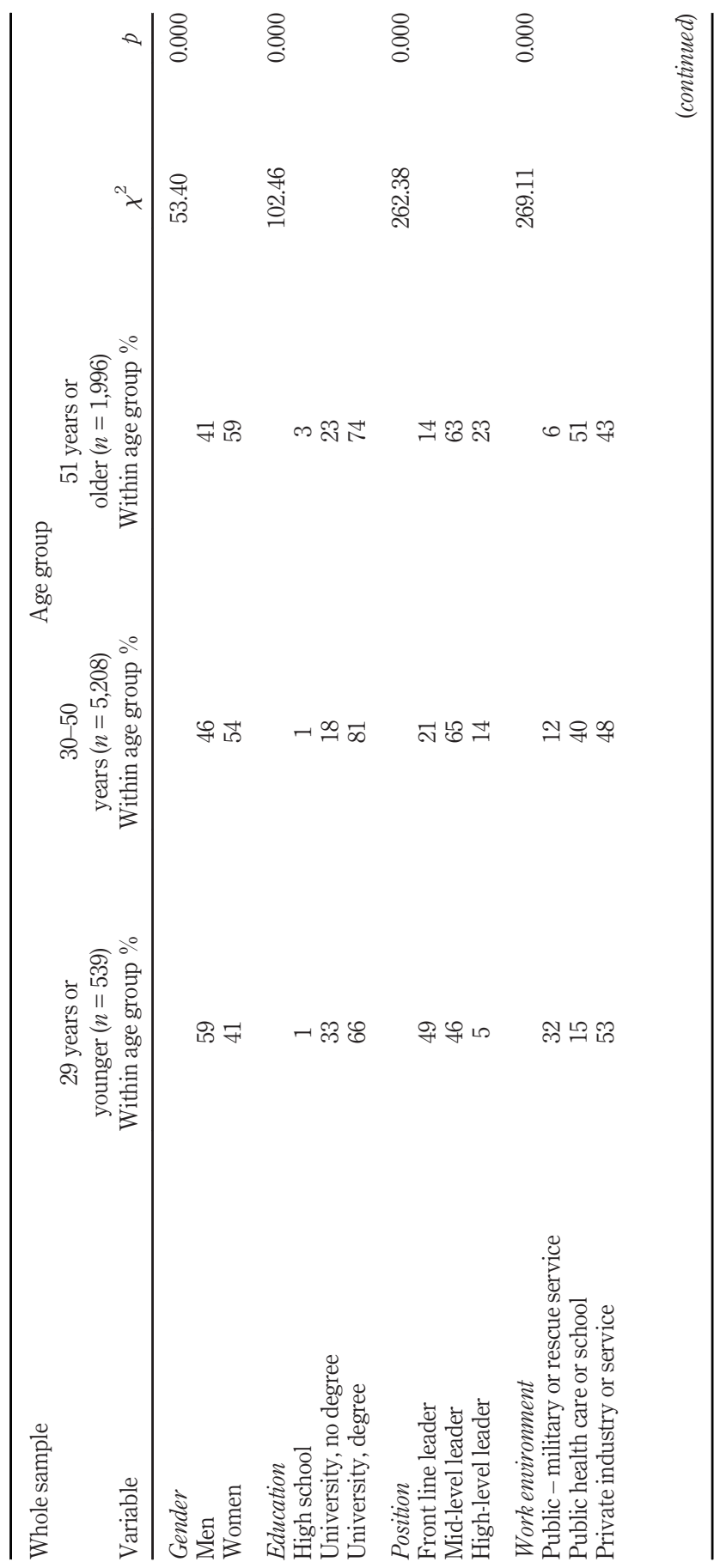




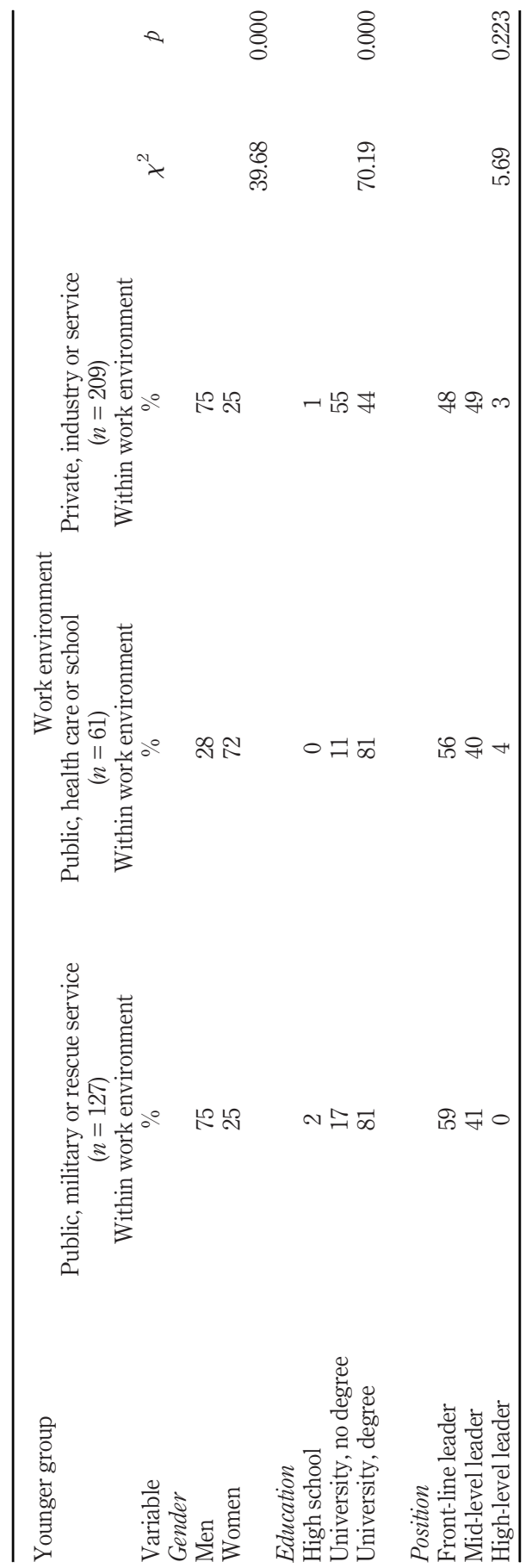

Comparisons of age groups

667 
MRR 44,5

\section{8}

Table 2.

Main study scales correlations (Pearson), means and standard deviations $(N=7,743)$ facets, namely, demand and reward - if, but only if, reward and control - over control. Sample item: "I keep a log of other people's mistakes." Finally, the destructive leadership style consists of 17 items designed to measure the two factors active destructive leadership and passive destructive leadership [incorporated into the DLQ from the instrument Destrudo-L, Larsson et al. (2012)]. Sample item: "I avoid making necessary decisions." A detailed description of the leadership dimensions, factors and facets can be found in Larsson et al. (2018).

The DLQ also contains items designed to measure the leader characteristic desirable competencies (Figure 1) as follows: task-related competence; two items, management-related competence; four items, social competence; two items and stress management skillrelated competence; four items. Finally, the instrument contains three items labeled results, which are designed to measure the outcome of leadership. Sample item: "I contribute markedly to increasing others' effectiveness".

Respondents are asked to judge how frequently they engage in the specific behavior described by each item. Each behavior is rated on a nine-point frequency scale ranging from never or almost never (1) to always or almost always (9). Pilot tests preceding the final version of the DLQ showed that most respondents preferred a nine-point scale and felt they could make meaningful differentiation between the scale steps. Scale scores were computed by adding the raw scores of the items representing the scale and dividing the sum by the number of items (scale scores could range from 1 to 9). Reliability (Cronbach's alpha) coefficients ranged between 0.75 and 0.96 .

\section{Statistics}

Comparisons between subgroups were performed using $t$-tests and one-way analysis of variance followed by Scheffé tests, the most conservative post hoc comparison method with respect to Type I errors. $\chi^{2}$ computations were performed to assess differences in the proportions of categorical background variables. Statistical significance was assumed at $p<0.05$. Because of a high number of mean comparisons, Bonferroni corrections were applied. When scale indices were computed (see above), only participants with complete scores on all items in a given index were included (listwise deletion). The numbers of participants shown in Tables 2 and 3 are consequently slightly lower than what is presented in Table 1. Finally, a theory-driven hierarchical logistic regression analysis was performed among the younger leaders, with self-rated results of leadership as a dependent variable.

\begin{tabular}{lrrrrrrrrrrr}
\hline Scale $^{\mathrm{a}}$ & 1 & 2 & 3 & 4 & 5 & 6 & 7 & 8 & 9 & $M$ & $S D$ \\
\hline 1. Developmental leadership & 1 & & & & & & & & & 7.19 & 0.75 \\
2. Conventional positive leadership & 0.70 & 1 & & & & & & & 7.34 & 0.82 \\
3. Conventional negative leadership & -0.27 & -0.12 & 1 & & & & & & & 1.89 & 0.91 \\
4. Destructive leadership & -0.50 & -0.42 & 0.50 & 1 & & & & & & 1.72 & 0.61 \\
5. Task-related competence & 0.39 & 0.37 & -0.12 & -0.25 & 1 & & & & 7.24 & 1.26 \\
6. Management-related competence & 0.56 & 0.46 & -0.09 & -0.28 & 0.55 & 1 & & & & 6.72 & 1.25 \\
7. Social competence & 0.50 & 0.34 & -0.17 & -0.26 & 0.28 & 0.38 & 1 & & & 7.51 & 1.21 \\
8. Stress management-related competence & 0.54 & 0.43 & -0.17 & -0.36 & 0.34 & 0.42 & 0.42 & 1 & & 6.97 & 1.14 \\
9. Results & 0.69 & 0.55 & -0.17 & -0.42 & 0.40 & 0.57 & 0.44 & 0.50 & 1 & 7.11 & 1.00
\end{tabular}

Notes: ${ }^{a}$ All scales can range from 1 (lowest frequency) to 9 (highest frequency). All correlations are statistically significant $(p<0.001)$ 


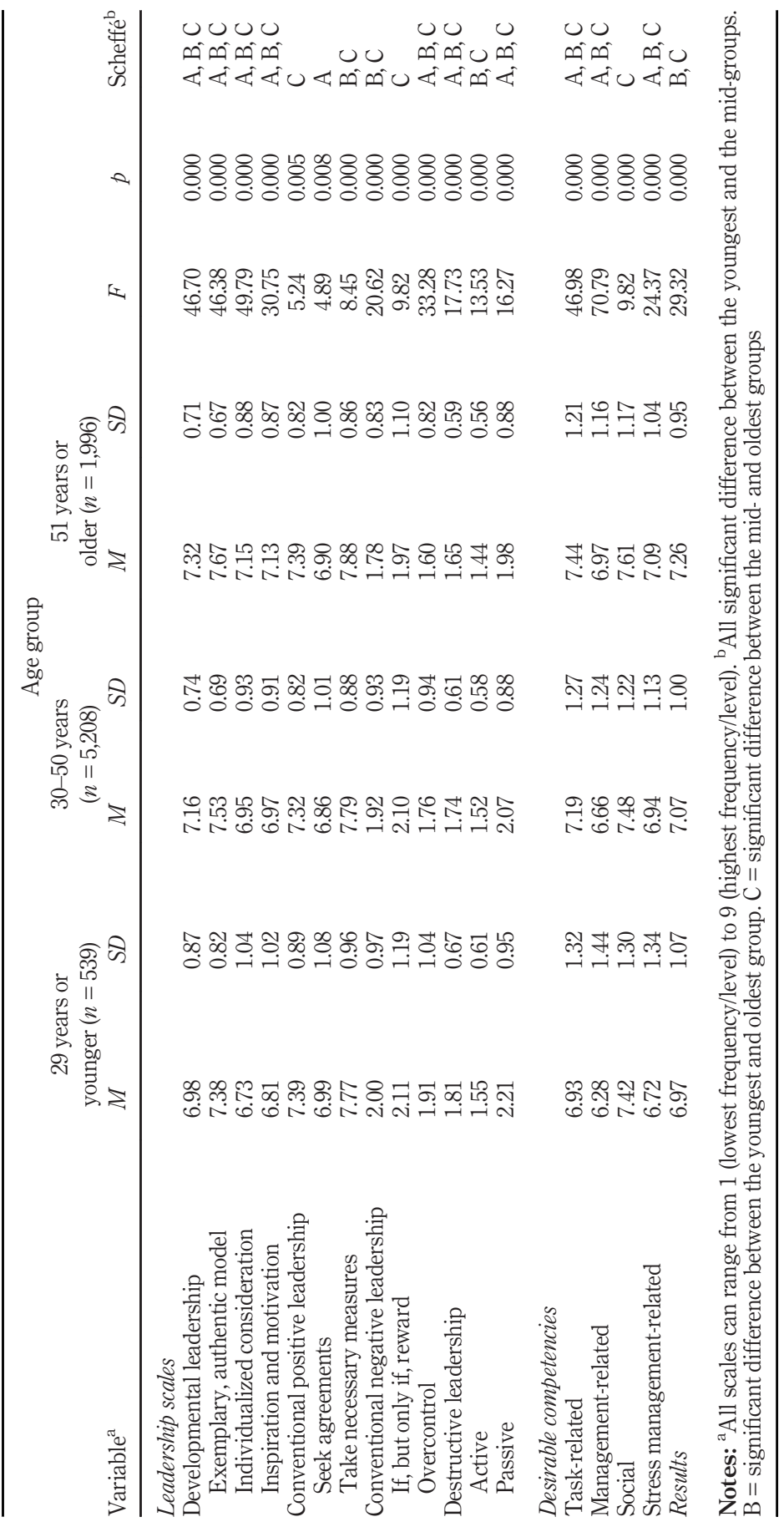

Comparisons of age groups

669

Table 3.

Comparison between leaders of different ages (one-way analysis of variance) 
MRR

44,5

\begin{abstract}
Results
Whole sample descriptive statistics

Table 2 shows that the participants rate themselves favorably. All bivariate correlations shown in the table are statistically significant at the $p<0.001$ level because of the high number of subjects.
\end{abstract}

Comparison between different age groups

Table 3 shows that the mean scores of the three age groups differ significantly on all scales designed to measure leadership styles, desirable competencies and results of leadership. All but two differences (conventional positive leadership and seek agreements) remain statistically significant after Bonferroni corrections ( $p$-values below 0.003 are required). The general pattern is that the younger group scores less favorably than the mid-aged and older groups.

\title{
Comparisons among the group of younger leaders
}

In the group of younger leaders, comparisons were made between different types of work environments and between men and women. The result of the work environment comparison is presented in Table 4 .

Table 4 shows significant differences between the mean scores of young leaders in different types of work environments on several scales. After Bonferroni corrections, the differences for developmental leadership (including the subscales individualized consideration and Inspiration and motivation) and for conventional negative leadership (including the subscales if, but only if, reward and overcontrol), remain significant. The general pattern is that young leaders in the private sector report the most favorable scores and those working in the military and the rescue services show the least favorable.

The second set of analyzes compared female and male young leaders ( $t$-tests). Female leaders tended to report more favorable scores than male leaders on the leadership style scales. The reverse was found on the scales designed to measure desirable competencies and results. However, after Bonferroni corrections, only the following four comparisons remained significant, with male leaders scoring higher (less favorable) on conventional negative leadership including the subscales if, but only if, reward and overcontrol, as well as on destructive leadership.

\section{Logistic regression analysis}

A hierarchical logistic regression analysis was performed on the group of younger leaders with the self-rated results of leadership as a dependent variable. Following the theoretical model (Figure 1), the desirable competence scales and the contextual variable type of work environment (categorical) were entered in Step 1 and the leadership scales in Step 2. The final model is summarized in Table 5 .

The final model was statistically significant, as were both steps. The percentage of correctly predicted individuals was 97.1 , the Cox and Snell $R^{2}$ was 0.696 and the Nagelkerke $R^{2}$ was 0.928 . As can be seen in Table 5 , social competence, developmental leadership and destructive leadership (negative association) contributed significantly.

\section{Discussion}

The first aim was to compare the self-rated leadership behaviors, leadership-related competencies and results of leadership, of younger, mid-aged and older leaders. The findings show that the group of younger leaders rated themselves more negatively than the 


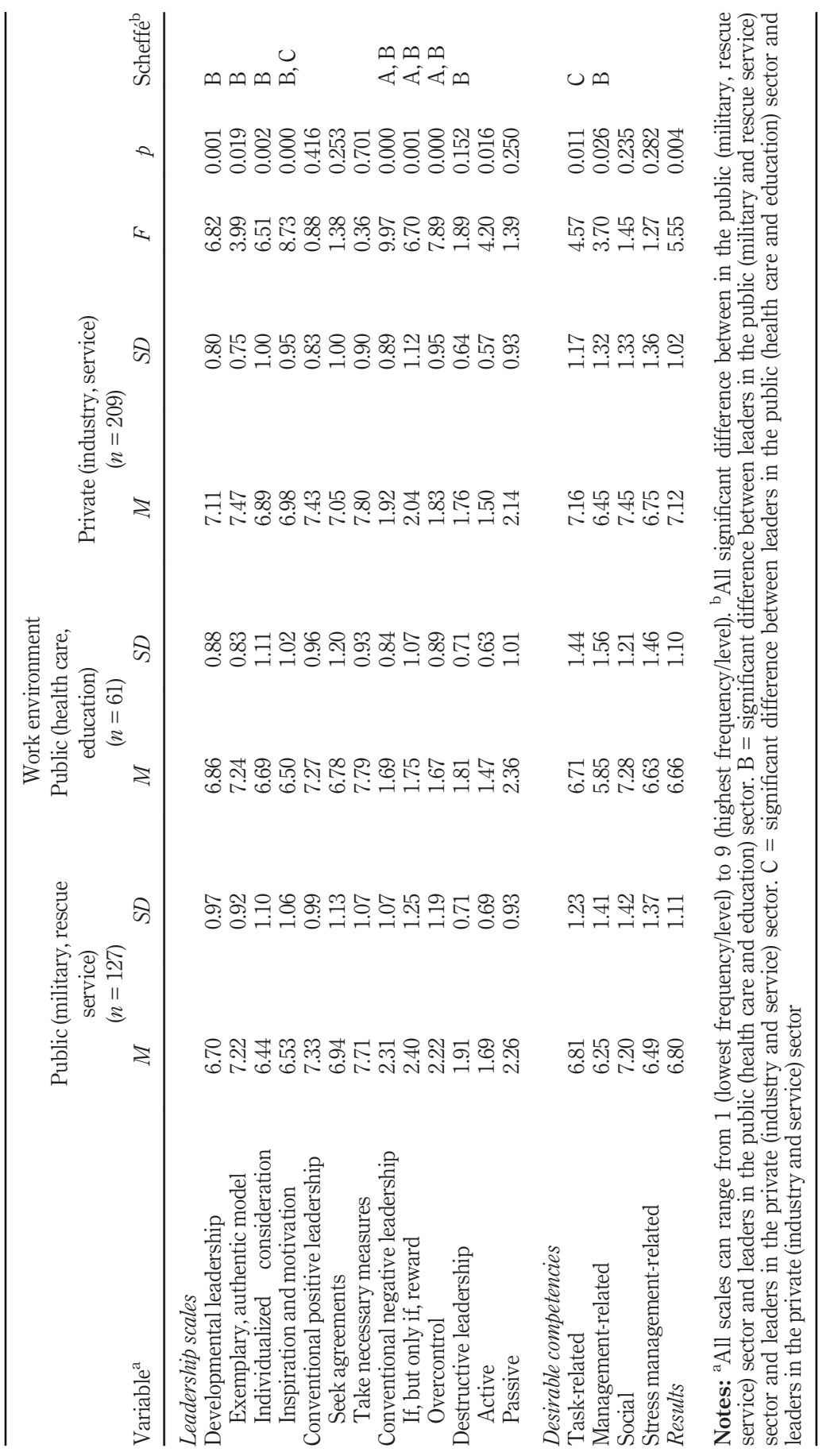

Comparisons of age groups

Table 4.

Comparison between young leaders in different work environments (oneway analysis of variance) 


\begin{tabular}{|c|c|c|c|c|c|c|c|}
\hline \multirow{4}{*}{$\begin{array}{l}\text { MRR } \\
44,5\end{array}$} & Predictor variable & $B$ & S.E. & Wald & $d f$ & Sign. & $\operatorname{Exp}(\mathrm{B})$ \\
\hline & Task-related competence & 0.562 & 0.801 & 0.493 & 1 & 0.483 & 1.775 \\
\hline & Management-related competence & 0.716 & 0.789 & 0.824 & 1 & 0.364 & 2.046 \\
\hline & Social competence & 1.857 & 0.930 & 3.987 & 1 & 0.046 & 6.404 \\
\hline \multirow[t]{2}{*}{672} & $\begin{array}{l}\text { Stress management-related } \\
\text { competence } \\
\text { Type of work environment - }\end{array}$ & -0.935 & 0.709 & 1.737 & 1 & 0.188 & 0.393 \\
\hline & $\begin{array}{l}\text { Private } \\
\text { Public, military }\end{array}$ & -0.704 & 1.279 & $\begin{array}{l}2.072 \\
0.303\end{array}$ & $\begin{array}{l}2 \\
1\end{array}$ & $\begin{array}{l}0.355 \\
0.582\end{array}$ & 0.494 \\
\hline \multirow{5}{*}{$\begin{array}{l}\text { Table 5. } \\
\text { Logistic regression } \\
\text { analysis - predictor } \\
\text { variables on results } \\
\text { (final model, young } \\
\text { group and } n=539 \text { ) }\end{array}$} & Public, health care & 3.032 & 2.255 & 1.809 & 1 & 0.179 & 20.746 \\
\hline & Developmental leadership & 8.161 & 2.540 & 10.327 & 1 & 0.001 & $3,503.182$ \\
\hline & $\begin{array}{l}\text { Conventional positive } \\
\text { leadership }\end{array}$ & 0.702 & 1.240 & 0.320 & 1 & 0.571 & 2.017 \\
\hline & Conventional negative & & & & 1 & & \\
\hline & $\begin{array}{l}\text { leadership } \\
\text { Destructive leadership }\end{array}$ & $\begin{array}{r}0.627 \\
-3.959\end{array}$ & $\begin{array}{l}0.980 \\
1.867\end{array}$ & $\begin{array}{l}0.410 \\
4.495\end{array}$ & $\begin{array}{l}1 \\
1\end{array}$ & 0.034 & 0.019 \\
\hline
\end{tabular}

mid-aged and older groups in all three areas. Thus, they reported less use of developmental (transformational) leadership behaviors and more negative conventional leadership behaviors and destructive leadership behaviors. They also presented lower self-ratings on scales designed to measure leadership-related competencies and results of leadership. One interpretation of these findings is that they reflect the challenges faced by newcomers in leadership positions. Having less experience, young leaders may find it more difficult to build trustful relationships with older subordinates and they may not yet have developed interpersonal competencies to handle issues of communication (Benjamin and O'Reilly, 2011; Uen et al., 2009).

The identical trend across all three measurement areas with the youngest group scoring least favorably indicates that the results are stable. An additional possible interpretation is that the results, which are in line with stereotype-based expectations (Bass and Bass, 2008), reflect a lack of self-confidence in the leadership role among young leaders and, perhaps, a self-inflicted impact of the stereotype expectations. Furthermore, how one rates oneself as a leader might be influenced by whether the young leaders have identified themselves as leaders or not and their experience before taking up a leadership position (Bolander et al., 2019). As this identity grows with experience, the length of time they have been in a leadership position is likely to affect their perception of themselves as leaders (Ibarra et al., 2010).

A wealth of research shows that developmental and conventional-positive leadership behaviors covary with various favorable individual and organizational outcomes (Bass and Riggio, 2006; Diaz-Sáenz, 2011). Other studies indicate even more strongly that destructive leadership covaries with negative outcomes (Einarsen et al., 2007; Larsson et al., 2012; Skogstad et al., 2007). To the degree that young leaders as a group act less in line with these general research findings than older leaders (as shown in the current study), it can be assumed that, at the group level, young peoples' leadership behaviors have a high potential for improvement. Organizational support in the form of development programs and mentoring could play an important role here (Benjamin and O'Reilly, 2011; DeLong et al., 2008).

The second aim of the study was to focus on young leaders and compare their self-rated leadership behaviors, leadership-related competencies and results of leadership in different 
types of the work environment and between men and women. With regard to the type of work environment, results showed that the young leaders who worked in the private sector scored most favorably. This could be because of there being a higher proportion of individuals working in competitive and rapidly changing environments, which foster positive leadership development (Antonakis, 2011; Bass and Bass, 2008). Thus, it seems reasonable that the results can be understood from an organizational culture perspective (Brown, 1997; Schein, 1992). However, the selection hypothesis cannot be ruled out. According to this hypothesis, certain personality types are attracted to certain kinds of jobs. There was some indication in the present study (although non-significant after Bonferroni corrections) that young leaders in the private sector have stronger leadership-related competencies. Thus, the favorable scores of those working in the private sector could also be a consequence of selection.

The comparison of men and women in the youngest group of leaders showed that men reported more use of conventional (transactional) negative leadership behaviors and destructive leadership behaviors. All other gender differences were non-significant after Bonferroni corrections. The results on the negative scales are in line with a recent study focusing on gender differences (Larsson and Alvinius, 2019).

The third aim was to analyze how a number of theoretically-derived predictor variables contribute to self-rated results of leadership among younger leaders. The outcome of the hierarchical logistic regression analysis showed that the model fitted the data well (a very high proportion of correctly predicted cased and high Cox and Snell $R^{2}$ and Nagelkerke $R^{2}$ coefficients respectively). The three individual variables that contributed significantly, social competence, developmental leadership and destructive leadership (negative), could all be said to deal with the softer aspects of leadership. The results indicate that those who perceived themselves favorably in these respects were satisfied with the outcome of their leadership and vice versa. These findings are in line with the suggestion above that organizational support such as development programs, mentoring and coaching are important. They also indicate which such efforts should be focused on.

One of the strengths of the study is that it is based on a fairly large sample of younger, mid-aged and older leaders and it uses a theory-based assessment tool of high reliability. A further strength is that it compares three different types of the work environment. However, it should be noted that the work environment categories are fairly broad and approximate. Someone who works in a health-care organization might, for instance, be the director of a university hospital, the head of a small ward or an Human Resources unit manager. Unfortunately, we do not have this kind of detailed data.

Another shortcoming is that the study is based on self-ratings collected at one point in time. Following from this, there is a risk of artificially inflated relationships among variables, so-called common method variance [CMV, Podsakoff, MacKenzie and Podsakoff (2012), Spector and Brannick (2010)]. In particular, there is a risk of responses being affected by social desirability in the present study. This refers to the tendency to present oneself favorably regardless of the true position on the construct being measured (Crown and Marlow, 1964). No markers of potential CMV influence were available. The study participants were leaders about to attend a leadership course, which used the pre-course questionnaire data as an important tool during the course. Thus, data collection was restricted to the DLQ. However, each leadership course participant was also rated anonymously on the same scales by 6 to 10 subordinates on the DLQ. A comparison between the leader's self-rating and the evaluations made by his or her subordinates, constitute a core part of the course. We believe the leaders' advance knowledge of this led them to refrain from presenting themselves in too favorable a fashion. Thus, given this data 
MRR 44,5

collection procedure, we regard the impact of CMV as limited. It would be desirable to have more objective data, as well as ratings made by superiors, peers and subordinates. Consequently, our first suggestion for further research includes obtaining more detailed data about the nature of the participants' jobs within a given work sector and data from sources other than self-ratings. A second suggestion is to conduct similar studies around the world to explore the possible effects of culture and socioeconomic conditions. The present data, set based on a well-educated Swedish sample, obviously restricts the generalizability of the findings.

One practical implication of the study is that its empirical results could be used in leadership development contexts and individualized coaching or mentoring programs. A second implication is that there is a need to explore and take action against the higher frequency of negative leadership behaviors among young leaders, especially young men.

\section{References}

Antonakis, J. (2011), "Predictors of leadership: the usual suspects and the suspect traits.", in Bryman, A., Collinson, D., Grint, K., Jackson, B. and Uhl-Bien, M. (Eds), The SAGE Handbook of Leadership, SAGE, London, pp. 269-285.

Åkerblom, C. (2011), "Ledarskap, makt och känsla: En narrativ studie av unga ledare. [leadership, power and emotion: a narrative study of young leaders]", Doctoral thesis, Royal Institute of Technology, Stockholm.

Bass, B.M. and Bass, R. (2008), The Bass Handbook of Leadership: Theory, Research, and Managerial Applications, Free Press, New York, NY.

Bass, B.M. and Riggio, R.E. (2006), Transformational Leadership: Industry, Military, and Managerial Applications, Free Press, New York, NY.

Benjamin, B. and O'Reilly, C. (2011), "Becoming a leader: early career challenges faced by MBA graduates", Academy of Management Learning and Education, Vol. 10 No. 3, pp. 452-472.

Björklund, C., Lohela Karlsson, M., Jensen, J. and Bergström, G. (2013), "Hierarchies of health: the health and work-related stress of managers in municipalities and county councils in Sweden", Journal of Occupational and Environmental Medicine, Vol. 55 No. 7, pp. 752-760.

Bolander, P., Holmberg, I. and Fellbom, E. (2019), "Learning to become a manager: the identity work of first-time managers", Management Learning, Vol. 50 No. 3, pp. 1-20.

Brown, A.D. (1997), "Narcissism, identity, and legitimacy", Academy of Management Review, Vol. 22 No. 3, pp. 643-686.

Corsini, R.J. (1999), "Stereotype”, in the Dictionary of Psychology, Brunner/Mazel, Philadelphia PA.

Crown, D.P. and Marlow, D. (1964), The Approval Motive: Studies in Evaluative Dependence, John Wiley, New York, NY.

DeLong, T.J., Gabarro, J.J. and Lees, R.J. (2008), "Why mentoring matters in a hypercompetitive world”, Harvard Business Review, Vol. 86 No. 1, p. 115.

Diaz-Sáenz, H.R. (2011), “Transformational leadership”, in Bryman, A., Collinson, D., Grint, K., Jackson, B. and Uhl-Bien, M. (Eds), The SAGE Handbook of Leadership, SAGE, Los Angeles, pp. 299-310.

Einarsen, S., Aasland, M.S. and Skogstad, A. (2007), "Destructive leadership behaviour: a definition and conceptual model”, The Leadership Quarterly, Vol. 18 No. 3, pp. 207-216.

Endler, N.S. and Magnusson, D. (1976), “Toward interactional psychology of personality”, Psychological Bulletin, Vol. 83 No. 5, pp. 956-979.

Fjällberg, U. (2012), "Stopp för unga i toppen [stop for the young at the top]", Veckans Affärer, pp. 50-52. 
Franzén, C., Linghag, S., \&., and Zander, S. (2002), ArbetsgläDje i Livet: om Ledarskap Pa ${ }^{3}$ 2000-Talet [Work Satisfaction in Life: About Leadership in the 21st Century], Näringslivets ledarskapsakademi, Stockholm.

Gardner, W.J., Avolio, B.J. and Walumbwa, F.O. (Eds) (2005), Authentic Leadership Theory and Practice: Origins, Effects and Development, Elsevier Jai, Amsterdam.

Hill, L.A. (1992), Becoming a Manager: Mastery of a New Identity, Harvard Business School, Boston, MA.

Ibarra, H., Snook, S. and Ramo, L. (2010), "Identity-based leader development”, in Khurana, R. and Noria, N. (Eds), Handbook of Leadership Theory and Practice, Harvard Business Press, Boston, MA, pp. 657-678.

Ipsen, C. and Jensen, L.P. (2012), "Organizational options for preventing work-related stress in knowledge work", International Journal of Industrial Ergonomics, Vol. 42 No. 4, pp. 325-334.

Kakabadse, A., Kakabadse, N. and Myers, A. (1998), "Demographics and leadership philosophy: exploring gender differences", Journal of Management Development, Vol. 17 No. 5, pp. 351-388.

Larsson, G. (2006), "The developmental leadership questionnaire (DLQ): some psychometric properties”, Scandinavian Journal of Psychology, Vol. 47 No. 4, pp. 253-262.

Larsson, G. and Alvinius, A. (2019), "Comparisons within gender and between female and male leaders in female-dominated, male-dominated and mixed-gender work environments", Journal of Gender Studies, pp. 1-12, doi: 10.1080/09589236.2019.1638233.

Larsson, G. and Hyllengren, P. (2013), "Contextual influences on leadership: theoretical modelling and empirical tests”, International Journal of Organizational Analysis, Vol. 21 No. 1, pp. 19-37.

Larsson, G., Fors Brandebo, M. and Nilsson, S. (2012), "Destrudo-L: development of a short scale designed to measure destructive leadership behaviours in a military context", Leadership and Organization Development Journal, Vol. 33 No. 4, pp. 383-400.

Larsson, G., Lundin, J. and Zander, A. (2018), The Leadership Model: The Art of Matching Individual and Organizational Characteristics, Studentlitteratur, Lund.

Larsson, G., Carlstedt, L., Andersson, J., Andersson, L., Danielsson, E., Johansson, A., Johansson, E., Michel, P.O. and Robertson, I. (2003), "A comprehensive system for leader evaluation and development”, Leadership and Organization Development Journal, Vol. 24 No. 1, pp. 16-25.

Ledarna (2014), En Chefsroll För Framtiden [a Manager Role for the Future], Ledarnas framtidsbarometer.

Ligon, G., Wallace, J. and Osburn, H. (2011), "Experiental development and mentoring processes for leaders' innovation”, Advances in Developing Human Resources, Vol. 13 No. 3, pp. 297-317.

Lyons, S. and Kuron, L. (2014), "Generational differences in the workplace: a review of the evidence and directions for future research”, Journal of Organizational Behavior, Vol. 35 No. S1, pp. S139-S157.

Oshagbemi, T. (2004), "Age influences on the leadership styles and behaviours of managers", Employee Relations, Vol. 26 No. 1, pp. 14-29.

Podsakoff, P.M., Mackenzie, S.B. and Podsakoff, N.P. (2012), "Source of method bias in social science research and recommendations on how to control it", Annual Review of Psychology, Vol. 63 No. 1, pp. $531-544$.

Prensky, M. (1998), “Twitch speed”, Across the Board, Vol. 35 No. 1, pp. 10-14.

Rorstorm, K. (2005), "Unga chefer vill inte styra i gammal stil [young managers do not want to rule in the old style]", Sydsvenskan, available at: www.sydsvenskan.se/ekonomi/unga-chefer-vill-intestyra-i-gammal-stil/

Schein, E.H. (1992), Organizational Culture and Leadership, 2nd ed., Jossey-Bass, San Francisco, CA.

Skakon, J. and Kristensen, T.S. (2011), "Do managers experience more stress than employees? results from the intervention project on absence and well-being (IPAW) study among danish managers and employees", Work, Vol. 38 No. 2, pp. 103-109. 
MRR

44,5

Skogstad, A., Einarsen, S., Torsheim, T., Aasland, M.S. and Hetland, H. (2007), “The destructiveness of laissez-faire leadership behavior", Journal of Occupational Health Psychology, Vol. 12 No. 1, pp. 80-92.

Spector, P.E. and Brannick, M.T. (2010), "Common method issues: an introduction to the feature topic in organizational research method", Organizational Research Methods, Vol. 13 No. 3, pp. 403-406.

Swedish Research Council (2002), Forskningsetiska Principer Inom Humanistisk-Samhälsvetenskaplig Forskning. [Research Ethical Principles in Humanistic-Social Research], Swedish Research Council, Stockholm.

Tulgan, B. (2011), "Generation Y: all grown up and now emerging as new leaders", Journal of Leadership Studies, Vol. 5 No. 3, pp.77-81.

Uen, J., Wu, T. and Huang, H. (2009), "Young managers' interpersonal stress and its relationship to management development practices: an exploratory study", International Journal of Training and Development, Vol. 13 No. 1, pp. 38-52.

Vision (2018), “Unga vill bli chefer [young people want to become managers]", available at: https:// vision.se/nyheter/2018/augusti/unga-vill-bli-chefer/

\section{Corresponding author}

Gerry Larsson can be contacted at: gerry.larsson@fhs.se

For instructions on how to order reprints of this article, please visit our website: www.emeraldgrouppublishing.com/licensing/reprints.htm

Or contact us for further details: permissions@emeraldinsight.com 